\title{
Kepemimpinan efektif melalui kompetensi komunikasi di Media Nusantara Citra Group
}

\begin{abstract}
ABSTRAK
Keberhasilan komunikasi dalam organisasi sangat bergantung pada kemampuan komunikasi pemimpinnya. Terkait dengan hal itu, penelitian ini bertujuan menganalisis pengaruh core communication skills, managerial communication skills, dan corporate communication skills yang dilakukan oleh Hary Tanoesoedibjo di Media Nusantara Citra Group (MNC Group) terhadap komunikasi kepemimpinan. Dasar pemikiran penelitian ini adalah perspektif struktural fungsional. Metode penelitian yang digunakan adalah survei dengan populasinya adalah karyawan tetap MNC Group mulai manajer ke atas, berjumlah 1088 orang. Jumlah sampel dihitung dengan rumus Taro Yamane didapat hasil sebanyak 100 responden. Teknik pengambilan sampel menggunakan probability sampling dengan teknik simple random sampling. Teknik analisis data dengan product moment Pearson dan melakukan analisis uji hipotesis dengan regresi linier berganda. Hasil penelitian menunjukan ketiga variabel independen yaitu core communication skills, managerial communication skills, dan corporate communication skills secara parsial maupun simultan memengaruhi effective leadership communication, karena indikator-indikator dalam ketiga variabel independen dapat mendukung terjadinya komunikasi internal perusahaan secara efektif. Simpulannya, tanpa memenuhi indikator-indikator dalam communication skills, maka seorang pemimpin akan cenderung gagal dalam melakukan komunikasi secara internal dalam perusahaan, baik dengan jajaran direksi atau komisaris maupun para pegawai secara keseluruhan. Kesemua indikator dalam penelitian ini, setelah disesuaikan dengan visi, misi, program dan kondisi perusahaan, disarankan untuk dijadikan sebagai standar keterampilan yang harus dimiliki oleh Chairman MNC terutama di masa depan.
\end{abstract}

Ahmad Mulyana ${ }^{1}$, Farid Hamid ${ }^{2}$, Suraya Mansur ${ }^{3}$, Susilawati ${ }^{4}$

1,2,3,4, Universitas Mercu Buana, Jakarta, Indonesia

Kata-kata Kunci: Komunikasi organisasi; komunikasi inti; komunikasi manajerial; komunikasi perusahaan; komunikasi internal

\section{Effective leadership through communication competence in Media Nusantara Citra Group}

\section{ABSTRACT}

The success of communication in an organization is very dependent on the communication skills of its leaders. With it, this study aims to analyze the influence of core communication skills, managerial communication skills, and corporate communication skills conducted by Hary Tanoesoedibjo at Media Nusantara Citra Group (MNC Group) on leadership communication. The rationale for this research is the perspective of functional structural. The research method used surveys with a population of permanent employees of MNC Group, starting with managers upwards, totaling 1088 people. The Taro Yamane formula calculates the number of samples in the result of 100 respondents. The sampling technique uses probability sampling with a simple random sampling technique data analysis techniques with Pearson product-moment and analysis of hypothesis testing with multiple linear regression. The results showed the three independent variables, namely core communication skills, managerial communication skills, and corporate communication skills; partially or simultaneously, it affects effective leadership communication because the indicators in the three independent variables can support the occurrence of internal corporate communication effectively. In conclusion, without fulfilling indicators in communication skills, a leader will tend to fail in communicating internally within the company. That is both with the board of directors or commissioners as well as the employees as a whole. All indicators in this study, after adjusting to the company's vision, mission, program, and conditions, are suggested to be used as a skill standard that must be owned by the Chairman of $M N C$, especially in the future.

Keywords: Organizational communication; core communication; managerial communication; corporate communication; internal communication

Korespondensi: Dr. Suraya Mansur. Universitas Mercu Buana Jakarta, J1. Meruya Selatan No.1, RT.4/RW.1, Meruya Sel., Kec. Kembangan, Kota Jakarta Barat, Daerah Khusus Ibukota Jakarta 11650. Email: suraya. suraya@mercubuana.ac.id

Submitted: April 2019 Accepted: October 2019, Published: December 2019 


\section{PENDAHULUAN}

Efektivitas kepemimpinan untuk sebagian besar masih tergantung pada masalah komunikasi. menyatakan "effective leadership is still largerly a matter of communication" demikian dinyatakan oleh Axelrod (Barret, 2013). Komunikasi pemimpin termasuk dalam komunikasi korporat, dan menjadi bagian dari public relations. Dalam konteks public relations, terdapat perbedaan antara teknisi komunikasi dan manager komunikasi. Teknisi komunikasi terkait dengan pekerjaan "PR" profesional seperti menulis news-release, menyusun draft pidato, memproduksi video, mengedit newsletter, mengorganisasikan iklan, dan seterusnya. Sementara itu, manajer komunikasi menyangkut manajer taktis (tactial manager) yang menyangkut keputusan harian pada isu prkatis dan spesifik, dan manajer strategis (strategic manager) yang menyangkut kecenderungan, kebijakan, isu penting, dan menyangkut struktur perusahaan (Smith, 2013).

Seorang pemimpin harus mampu berkomunikasi secara efektif, karena 70-90\% pekerjaan harian pemimpin organisasi terdiri atas rangkaian komunikasi (Barret, 2013). Efektivitas komunikasi pemimpin dalam internal perusahaannya harus tercermin dalam lima aspek, yakni supportive management, targeted messages, effective media/forum, well-positioned staff, dan ongoing assessment (Barret, 2013). Keterampilan komunikasi menjadi hal wajib yang mutlak dimiliki oleh seorang pemimpin. Hal tersebut dikarenakan dalam menjalankan aktivitasnya seorang pemimpin banyak melakukan komunikasi, baik dengan kalangan internal maupun eksternal perusahaannya.

Salah satu pemimpin organisasi bisnis, seorang Chief Executive Officer (CEO) yang namanya cukup populer antara lain Hary Tanoesoedibjo. Hary Tanoesoedibjo cukup populer, karena wajah dan berita mengenai aktivitasnya banyak menghiasi media massa. Hary Tanoesoedibjo adalah salah seorang pebisnis Indonesia yang saat ini kiprahnya sedang terus menanjak. Hary Tanoesoedibjo berada di balik berkembangnya PT Media Nusantara Citra Tbk, yang lebih dikenal sebagai MNC Corporation atau MNC Group.

MNC Group sendiri merupakan satu korporasi di Indonesia yang sedang berkembang pesat. PT Media Nusantara Citra Tbk, yakni perusahaan yang didirikan 17 Juni 1997, sahamnya telah tercatat pada Bursa Efek Indonesia per 22 Juni 2007. Bisnis MNC Group terdiri atas tiga sektor, yakni sektor media-massa, sektor jasa keuangan, dan sektor properti. Sektor media massa yaitu MNC Media terdiri atas broadcasting-media, dalam hal ini stasiun free-to-air TV (empat televisi komersial nasional: RCTI, Global TV, MNC TV dan iNews TV) dan televisi berbayar yang menghadirkan 22 saluran pada MNC Channel. Sektor media-massa ini merambah ke mediamassa cetak (Koran Sindo, tabloid Genie, Mom, dan Het), radio (MNC radio) maupun Internet (Indovision, okezone.com, dan mr.aladin.com).

Sektor jasa keuangan MNC meliputi asuransi (MNC Insurance, MNC Life, MNC Asset Management), pasar bursa (MNC Securities), bank (MNC Bank), investasi (MNC Financial Investment), leasing (MNC Leasing). Sementara itu sektor properti terdiri atas mall (Plaza Indonesia Complex, Plaza Indonesia Shopping Center, Indonesia Plaza Office); perhotelan (Grand Hyatt Jakarta, Park Hyatt Hotel Jakarta, Westin Resort Nusa Dua Bali, Trump International Hotel Bali, merupakan kerja sama bisnis Hary Tanoesoedibjo dengan Donald Trump, dan Pan Pacific Nirwana Bali Resort), kemudian yang segera akan direalisasi adalah perumahan dan theme park sekelas Disney Land di Lido, Jawa Barat.

Sukses Hary Tanoesoedibjo membangun bisnis MNC Group tidak terlepas dari kepiawaiannya dalam berkomunikasi pada internal korporasinya maupun dengan pihak eksternal perusahaan, sehingga bisa bergaul dengan baik dengan para tokoh politik nasional, pengusaha nasional, hingga mampu menggaet pengusaha kelas dunia seperti Donald Trump (kini presiden Amerika Serikat) untuk menjadi mitra bisnisnya. Hary Tanoesoedibjo juga dikenal sebagai pembicara bisnis di dalam maupun di luar negeri. Berdasarkan catatan dari sumber di MNC Group, Hary Tanoesoedibjo telah menyampaikan kuliah umum pada 170 perguruan tinggi di Indonesia, baik perguruan tinggi negeri maupun swasta.

Alasan penelitian ini memilih Hary Tanoesoedibjo karena beliau merupakan Chairman \& CEO dari sebuah grup perusahaan yang berkembang dengan baik dalam tempo 20 tahun. Pada tahun 2015, di saat perekonomian 
Indonesia sedang dalam keadaan yang tidak terlalu menggembirakan, jumlah karyawan MNC terus bertambah hingga lebih dari 30 ribu orang. Selain itu Hary Tanoesoedibjo menangani tiga sektor usaha yang berbeda. Bahkan, MNC media dinobatkan sebagai a Southeast Asia's Largest and Most Integrated Media. Sebagai seorang Chairman \& CEO Hary Tanoesoedibjo sangat intensif melakukan komunikasi verbal maupun nonverbal secara sistematis, seperti berbicara pada Manager Forum yang dihadiri sekitar 800 manager up dari MNC Group. Bukti lain Hary Tanoesoedibjo businessman yang patut diperhitungkan adalah adanya pengakuan dari majalah Forbes yang memberikan penghargaan kepada Hary Tanoesoedibjo pada tahun 2016 sebagai Businessman of The Year pengusaha sukses di Indonesia dan kancah regional, dengan alasan kinerja MNC Group sepanjang tahun 2015. Memperkuat penghargaan ini, majalah Forbes menampilkan foto Hary Tanoesoedibjo sebagai sampul majalah Forbes Indonesia edisi Januari 2016, volume 1 issue 1.

Pesatnya perkembangan bisnis $\mathrm{MNC}$ Group tidak terlepas dari strategi dan keterampilan komunikasi Hary Tanoesoedibjo dalam mensosialisasikan visi, misi, nilainilai budaya hingga strategi bisnisnya kepada segenap jajaran manajer MNC Group. Salah satu wahana komunikasi internal Hary Tanoesoedibjo bagi kalangan manajer pada MNC Group adalah Manager Forum. Manager Forum adalah kegiatan rutin tiga bulanan yang diselenggarakan oleh MNC Group. Pesertanya adalah level manajer ke atas dari seluruh unit bisnis yang ada di MNC Group. Jumlah peserta yang hadir terus berkembang sesuai dengan perkembangan perusahaan. Hingga pelaksanaan Manager Forum XXVIII pada 10 Juli 2017 jumlah pesertanya 1088 orang terdiri dari 744 berasal dari sektor media, 278 dari sektor jasa keuangan \& investasi dan 66 dari sektor properti. Acara berlangsung selama setengah hari mulai pukul 14.00-18.00 berakhir dengan ramah tamah disertai makan bersama.

Penelitian pendahuluan dilakukan dengan menyebarkan kuesioner kepada 30 manajer MNC Group secara insidental, yakni siapa saja 30 manajer pertama yang dapat ditemui penulis. Kuesioner dengan menggunakan skala Likert yang terdiri atas lima pernyataan yang merupakan lima isu kelemahan komunikasi Hary Tanoesoedibjo selama ini. Hasil penelitian pendahuluan dengan melihat rata-rata (mean) tersebut tampak pada tabel 1 .

Berdasarkan hasil penelitian pendahuluan tersebut tampak bahwa kelima item pernyataan, nilai rata-ratanya-nya hampir mendekati 4,0 (setuju). Hal ini berarti responden menyetujui kelima item pernyataan dalam kuesioner yang secara keseluruhan merupakan isu negatif mengenai komunikasi Hary Tanoesoedibjo. Dengan kata lain, sejauh ini terjadi permasalahan dalam komunikasi Hary Tanoesoedibjo. Oleh karena itu, masalah ini menarik untuk diteliti lebih lanjut.

Penelitian ini bertujuan untuk mengetahui sejauhmana core communication skills, managerial communication skills, dan corporate communication skills secara simultan berpengaruh terhadap effective leadership communication. Teori yang digunakan adalah struktural fungsional atau teori fungsionalisme struktural (structural functionalism) atau sering disederhanakan menjadi fungsionalisme

Tabel 1 Hasil Penelitian Pendahuluan

\begin{tabular}{|c|c|c|}
\hline No. & Pernyataan & Rata-Rata \\
\hline 1 & $\begin{array}{l}\text { Dalam berkomunikasi, } \\
\text { Chairman MNC Group } \\
\text { kurang dalam melakukan } \\
\text { sentuhan pribadi } \\
\text { (personal touch) }\end{array}$ & 3,87 \\
\hline 2 & $\begin{array}{l}\text { Dalam berkomunikasi, } \\
\text { Chairman MNC Group } \\
\text { terkesan menjaga jarak } \\
\text { dengan para karyawan }\end{array}$ & 3,87 \\
\hline 3 & $\begin{array}{l}\text { Dalam berkomunikasi, } \\
\text { Chairman MNC Group } \\
\text { terkesan sangat formal }\end{array}$ & 3,97 \\
\hline 4 & $\begin{array}{l}\text { Dalam berkomunikasi, } \\
\text { Chairman MNC Group } \\
\text { kurang humoris }\end{array}$ & 3,87 \\
\hline 5 & $\begin{array}{l}\text { Dalam kantor sehari- } \\
\text { hari Chairman MNC } \\
\text { Group terkesan hanya } \\
\text { berkomunikasi dengan } \\
\text { kalangan direksi dan } \\
\text { komisaris }\end{array}$ & 3,87 \\
\hline & Jumlah rata-rata & 3,89 \\
\hline
\end{tabular}

Sumber: Hasil penelitian pendahuluan, 2017 
(functionalism) yang diperkenalkan Talcott Parsons (Lahoreschool, 2017).

Pemikiran Parsons yang lebih mensintesiskan pemikiran Durkheim dan Weber menyatakan bahwa sistem sosial terbentuk oleh aksi-aksi individual. Interaksi antara dua individual atau lebih, berhadapan dengan variasi pilihan mengenai bagaimana mereka bertindak, pilihan yang dipengaruhi dan dibatasi oleh sejumlah faktor fisik maupun sosial. Setiap individu memiliki ekspektasi dari aksi dan reaksi pihak lain terhadap perilaku individu tersebut. Jika harapan individu tersebut terpenuhi (sukses), berarti harapan-harapan individu tersebut berasal dari norma dan nilai yang diterima dalam masyarakat. Parsons mengakui, dalam konteks umum, tidak pernah ada kecocokan yang sempurna (perfect fit) antara perilaku (behaviors) dan norma (norms), sehingga hubungan tersebut tidak pernah komplit atau sempurna (Lahoreschool, 2017).

Secara tradisional, komunikasi dipandang sebagai sebuah proses sederhana, yakni pengirim pesan (the sender) mentransmisikan pesan (message) kepada penerima (receiver). Penerima pesan tersebut diasumsikan dapat memahami dan bertindak sesuai pesan yang disampaikan pengirim pesan (Johansson, Miller, \& Hamrin, 2014).

Komunikasi korporat pada dasarnya berasal dari komunikasi secara umum dari Aristoteles yang memandang tiga komponen dalam komunikasi. Komponen pertama adalah subjek yang berbicara, yang dalam komunikasi korporat berarti organisasi. Komponen kedua sebagai pendengar versi Aristoteles, dalam organisasi berarti audiens. Komponen ketiga yang dideskripsikan Aristoteles sebagai:"subjek yang diperlakukan" berarti pesan atau message (Argenti, 2010).

Efektivitas komunikasi korporat tidak terlepas dari kerangka Aristoteles tersebut. Strategi komunikasi korporat yang efektif meliputi: a) menentukan tujuan bagi komunikasi tertentu, b) memutuskan sumber daya apa yang tersedia untuk mencapai tujuan tersebut, dan c) mendiagnosis reputasi organisasi (Argenti, 2010).

Tujuan komunikasi suatu perusahaan tergantung dari tujuan perusahaan, misalnya perusahaan ingin mengumumkan penghapusan tunjangan kesehatan pensiunan sebagai dampak dari meningkatnya biaya perawatan. Dalam kasus ini tujuan komunikasi korporat tidak sekedar mengumumkan perubahan, namun tujuan komunikasi korporat hendak meyakinkan karyawan bahwa terdapat alasan yang rasional untuk mengambil tambahan pendanaan biaya perawatan dari karyawan. Tujuan komunikasi korporat berarti untuk membuat karyawan menerima perubahan tersebut dengan protes atau resistensi seminimal mungkin.

Dalam mencapai tujuan komunikasi, korporat juga harus memperhatikan reputasi korporat. Korporat harus menentukan kredibilitas citra macam apa yang dimiliki perusahaan dengan konstituennya. Kredibilitas citra didasarkan pada persepsi konstituen dari korporat daripada realitas korporat itu sendiri (Argenti, 2010).

Seorang pemimpin dituntut untuk dapat berkomunikasi dengan efektif, memiliki keterampilan komunikasi dengan baik (good communication skills). Seorang pemimpin lebih banyak menghabiskan waktunya untuk berkomunikasi, yang menurut penelitian menghabiskan 70-90 persen waktu mereka setiap harinya (Eccles \& Nohria, 1991). Itulah sebabnya mengapa keterampilan komunikasi seorang pemimpin patut digarisbawahi. Menguasai komunikasi pemimpin menjadi sebuah prioritas bagi para manajer yang menginginkan perusahaan atau komunitas usahanya dalam mempertimbangkan pemimpinnya.

Dalam dekade terakhir terjadi kebangkitan terjadinya mediatisasi antara masyarakat dan organisasi (Livingstone, 2009; Lundby, 2009). Publik semakin tertarik dengan kegiatan perusahaan. Pemangku kepentingan mengumpulkan informasi dari media massa atau media sosial. Pada akhirnya organisasi menjadi refleksif (Ruler \& Vercic, 2005). Perusahaanperusahaan tersebut menggunakan komunikasi strategis dan public relations (PR) sebagai praktisi profesional untuk mengelola aktivitas komunikasi dan hubungan antar organisasi dengan pemangku kepentingan organisasi mereka (Hallahan, Holtzhausen, Ruler, Vercic, \& Sriramesh, 2007).

Mengingat tugas utama dalam bidang komunikasi atas nama perusahaan adalah berada pada pundak CEO dan atasan lainnya, maka manajer menjadi wakil dan juru bicara perusahaan di media massa atau media sosial. Pada saat bersamaan cara komunikasinya 
harus dipantau dan dikelola sebagai bagian dari strategi komunikasi menyeluruh yang mencakup komunikasi finansial, internal dan pemasaran, serta publik (Christensen \& Cornelissen, 2010). Organisasi menggunakan faktor-faktor berita seperti personalisasi dalam strategi pengelolaan pesan (Nessmann, 2009), manajemen reputasi perusahaan (GainesRoss, 2008) dan manajemen impresi (Pollach \& Kerbler, 2011) kepada eksekutif top-nya. CEO kini telah memersonifikasikan dan mewakili organisasi melalui visibilitas di media. Dengan jalan demikian, kepemimpinan mereka mempengaruhi persepsi para pemangku kepentingan dalam organisasi tersebut, dan demikian mempengaruhi reputasi dan kinerja (Meng \& Berger, 2013).

Dalam hal keterampilan komunikasi pemimpin (leadership communication skills), Barret mengusulkan model spiral (Barret, 2013). Model spiral ini mendeskripsikan tiga level keterampilan komunikasi pemimpin. Level paling dasar dan berada pada bagian pusat dari spiral tersebut adalah keterampilan komunikasi inti (core commuications skills), kemudian maju keluar ke level kedua yakni keterampilan komunikasi manajerial (managerial communication skills), dan bagian spiral paling luar adalah ketrampilan komunikasi korporat (corporate communication skills).

Keterampilan komunikasi inti (core communication skils) adalah kemampuan

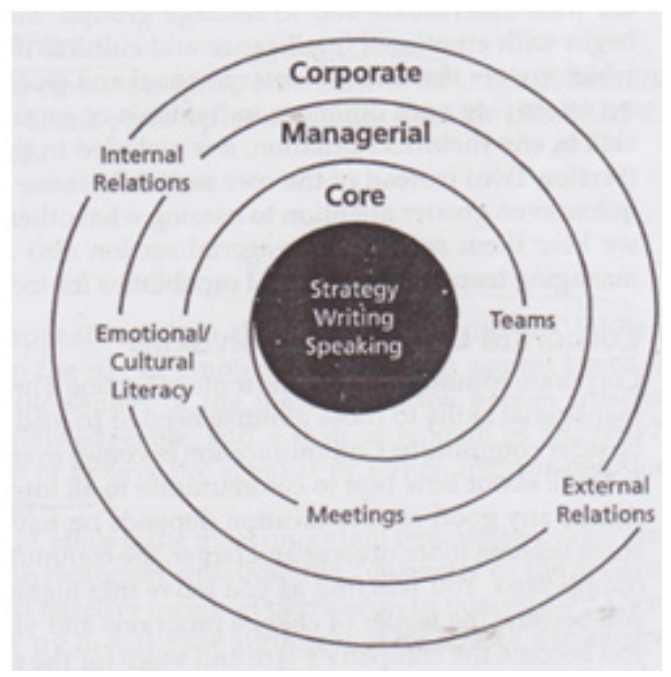

Sumber: Barret, 2006

Gambar 1 Komunikasi Pemimpin komunikasi pemimpin secara individualmeliputi kemampuan menulis secara terstruktur dan efektif yang berhubungan dengan korespondensi yang sederhana maupun kompleks, dari mulai e-mail, memo hingga proposal dan laporan. Keterampilan inti meliputi kemampuan berkomunikasi dalam bahasa sebagai pemimpin bisnis dengan bahasa yang jelas, benar dan ringkas. Selain itu keterampilan inti seorang pemimpin pun mencakup keterampilan berpidato dan melakukan presentasi secara persuasif dan meyakinkan, menggunakan grafik untuk menambah bobot komunikasi. Variabel keterampilan komunikasi inti meliputi tiga dimensi, yaitu: (i) dimensi analisis audience dan strategi, (ii) keterampilan komunikasi tertulis, dan (iii) keterampilan komunikasi lisan (Barret, 2013).

Keterampilan komunikasi manajerial (managerial communication skills) adalah kemampuan komunikasi yang berhubungan dengan bagaimana me-manage orang lain, dari mulai kontak antar perorangan, dengan kelompok, maupun organisasi secara lebih luas. Kemampuan komunikasi manejerial ini berkaitan dengan kecerdasan emosional (emotional intelligence) dan literasi budaya (cultural literacy), yang dibutuhkan untuk dapat berkomunikasi secara interpersonal maupun antarbudaya (cross-cultural). Keterampilan komunikasi manajerial ini juga termasuk keterampilan dalam memimpin rapat atau pertemuan maupun kemampuan me-manage tim (Barret, 2006). Variabel keterampilan komunikasi manajerial meliputi tiga dimensi, yaitu: (i) dimensi etos/citra, (ii) keterampilan dalam berurusan dengan orang lain, dan (iii) observasi dan keterampilan umpan balik (Barret, 2013).

Keterampilan komunikasi korporat (corporate communication skills) adalah kemampuan komunikasi yang lebih luas daripada keterampilan komunikasi manajerial. Keterampilan komunikasi menjadi lebih kompleks ketika seorang pemimpin harus melakukan komunikasi terbaik untuk pemangku kepentingan pada internal maupun eksternal perusahaan. Keterampilan komunikasi pada level ini dituntut lebih tinggi karena berkaitan dengan seorang pemimpin yang harus dapat menjelaskan mengenai perubahan program maupun pengembangan visi. Keterampilan komunikasi pada level ini juga dituntut lebih 
tinggi levelnya, karena berhubungan dengan posisi pemimpin sebagai wajah, citra dan suara perusahaan untuk publik (Barret, 2013).

Variabel keterampilan komunikasi korporat (corporate communication skills) meliputi 12 indikator. Ke-12 indikator tersebut menyangkut (1) pengembangan strategi komunikasi internal, (2) pengembangan visi, (3) mengkomunikasikan visi, (4) menargetkan pesan terhadap level yang berbeda dalam organisasi, (5) menciptakan program komunikasi yang mengalami perubahan. Kemudian, (6) menerapkan program komunikasi yang mengalami perubahan, (7) mengembangkan strategi komunikasi eksternal, (8) me-manage citra korporat, (9) menganalisis pemangku kepentingan eksternal, (10) menyusun pesan yang telah ditargetkan untuk semua pemangku kepentingan eksternal, (11) berkomunikasi dengan media berita, dan (12) berhadapan dengan situasi krisis dalam berkomunikasi (Barret, 2013). Ke-12 indikator ini yang akan diteliti untuk mengukur variabel keterampilan komunikasi korporat terhadap kepemimpinan yang efektif.

Salah satu tanggung jawab pemimpin suatu organisasi adalah berkomunikasi dengan karyawannya. Seorang pemimpin dinilai mampu berkomunikasi secara efektif dengan karyawannya, apabila pemimpin tersebut dapat menerjemahkan visi dan misi perusahaan dalam bahasa yang dipahami semua karyawan serta dirasakan bermakna oleh karyawan, dapat menerjemahkan arah kerja perusahaan pada tataran praktik sehari-hari, mampu menegakkan lingkungan kerja yang positif dan produktif, serta dapat mempengaruhi bottom lines dari perusahaan (Barret, 2013).

Komunikasi internal perusahaan yang efektif dapat memberikan arah organisasi dan memotivasi karyawan. Dampak dari komunikasi internal perusahaan yang efektif yang dilakukan seorang pemimpin adalah karyawan akan membantu pemimpin itu dalam mencapai visi dan misi perusahaan. Bahkan komunikasi internal perusahaan yang efektif juga berdampak pada kinerja perusahaan secara finansial. Suatu studi yang meneliti return on invesment (ROI) 267 perusahaan menunjukkan bahwa komunikasi internal perusahaan secara signifikan mempengaruhi kinerja perusahaan. Perusahaan dengan level yang paling tinggi dalam komunikasi yang efektif mencapai 26 persen ROI pada periode 1998-2002, berbanding dengan hanya 15 persen ROI bagi perusahaan yang komunikasi internalnya kurang efektif (Barret, 2013).

Komunikasi pemimpin yang efektif, harus mengandung dasar komunikasi pemimpin dengan karyawannya, dengan tujuan untuk (i) Mendidik karyawan terkait visi dan tujuan strategis perusahaan; (ii) Memotivasi karyawan agar mendukung strategi perusahaan; (iii) Mendorong kinerja dan upaya yang lebih tinggi daru segenap karyawan; (iv) Mengurangi kesalahpahaman dan gosip yang dapat merusak produktivitas; dan (v) Merangkul karyawan agar senantiasa berada di belakang dari target kinerja dan posisi perusahaan dan membantu mereka untuk mencapainya. Untuk mencapai keempat dasar komunikasi pemimpin yang efektif terhadap karyawannya, maka seorang pemimpin harus membuat pesan-pesannya terasa jelas, konsisten, dan memiliki target (Barret, 2013).

Adapun dimensi komunikasi pemimpin perusahaan yang efektif terdiri atas: manajemen yang mendukung (supportive management), (ii) pesan yang memiliki target (targeted messages), (iii) forum/media yang efektif (effective medial forum), (iv) staf yang ditempatkan dengan tepat (well-positioned staff), dan (v) penilaian yang berkelanjutan (ongoing assesment) (Barret, 2013).

Penelitian Yan Jin, Juan Meng dan Bruce $\mathrm{K}$ Berger menjelaskan bahwa komunikasi kepemimpinan yang berkualitas akan dapat mengatasi krisis secara efektif dalam perusahaan (Jin, Meng, \& Berger, 2017). Hipotesis penelitian ini adalah:

Hipotesis: Hipotesis teoritik yang digunakan dalam menjawab masalah (Okoro, Washington, \& Thomas, 2017) penelitian ini adalah sebagai berikut:

Hipotesis 1: Pengaruh Core communication skills berpengaruh terhadap effective leadership communication.

Hipotesis 2: Pengaruh Managerial communication skills berpengaruh terhadap effective leadership communication.

Hipotesis 3: Pengaruh Corporate communication skills berpengaruh terhadap effective leadership communication.

Hipotesis 4: Pengaruh Core communication skills, managerial communication skills, dan corporate communication skills secara simultan terhadap effective leadership communication. 


\section{METODE PENELITIAN}

Penelitian ini menggunakan paradigma positivistik. Pendekatan penelitian ini survei kuantitatif, dengan tipe penelitian kausal. Metode penelitian ini adalah korelasional. Dalam penelitian ini variabel yang diamati adalah pengaruh core communications skills, managerial communication skills, dan corporate communication skills) terhadap effective leadership communication.

Populasi yang digunakan pada penelitian ini adalah karyawan tetap MNC Group mulai manajer ke atas (manager up) yang menjadi peserta dalam Manajer Forum yang berjumlah 1088 orang. Perhitungan jumlah sampel dalam penelitian ini menggunakan rumus Tabachnick \& Fidell (Tabachnick \& Fidell, 2013) yakni:

$\mathrm{n} \geq 50+8 \mathrm{~m}$

$\mathrm{n}=$ jumlah sampel

$\mathrm{m}=$ jumlah variabel independen

Jumlah sampel minimal adalah $=50+$ $(8 \times 3$ variabel independen $)=74$ responden, yang dinaikkan menjadi 100 responden. Teknik pengambilan sampel yang digunakan probability sampling dengan teknik simple random sampling.

Pengujian reliabilitas dan validitas terhadap variabel core communication skills $\left(\mathrm{X}_{1}\right)$ managerial communication skills (X2), corporate communication skills (X3), dan effective leadership communication (Y) menunjukkan bahwa nilai Cronbach's Alpha masing-masing adalah 0,629 $\left(\mathrm{X}_{1}\right) ; 0,679\left(\mathrm{X}_{2}\right)$, $0,628\left(\mathrm{X}_{3}\right)$, dan 0,679(Y). Hal ini berarti masingmasing nilai Cronbach's Alpha lebih besar daripada 0.60 , sehingga item-item pernyataan pada kuesioner untuk variabel tersebut dapat dinyatakan reliable secara keseluruhan.

Teknik analisis data melakukan analisis uji hipotesis Regresi Linier Berganda. Model regresi linier berganda dalam penelitian ini disusun menggunakan nilai koefisien regresi unstandardized $B$ (untuk analisis pengaruh simultan) dan standardized beta (untuk analisis pengaruh parsial). Rumus regresi linier berganda adalah sebagai berikut:

$\mathrm{Y}=\beta 0+\beta_{1} \mathrm{YX}_{1}+\beta_{2} \mathrm{YX}_{2}+\beta_{3} \mathrm{YX}_{3}+\varepsilon$

Dimana;

Y: Effective leadership communications

$\beta 0$ : Koefisien konstanta

$\beta_{1}, \beta_{2}$, Koefisien regresi

$\mathrm{X}_{1}$ : Core communication skills
$\mathrm{X}_{2}$ : Managerial communications skills

$\mathrm{X}_{2}$ : Corporate communications skills

e: Error (outlier)

Analisis data menggunakan taraf signifikansi Alpha 0,05.

\section{HASIL DAN PEMBAHASAN}

Penyebaran kuesioner dilakukan secara langsung (tatap muka) kepada masing-masing responden. Setelah melalui seleksi, diperoleh 100 responden yang layak dilanjutkan untuk proses penelitian selanjutnya. Mayoritas responden $(59,0 \%)$ adalah laki-laki, barulah sisanya $(41,0 \%)$ adalah perempuan. Hal ini sesuai dengan kecenderungan jumlah managerup di MNC Group yang lebih banyak laki-laki daripada perempuan. Dari segi usia, mayoritas (86\%) merupakan manager-up yang berusia antara 36 hingga 50 tahun. Usia di bawah dan setelah rentang 36-50 tahun (7,0\%).

Ditinjau dari tingkat pendidikan, mayoritas responden $(83,0 \%)$ adalah lulusan $\mathrm{S} 1,13 \%$ lulusan S2, dan hanya 4\% lulusan diploma. Dilihat dari masa kerja, mayoritas responden $(84,0 \%)$ adalah mereka yang sudah bekerja relatif lama, minimal tujuh tahun kerja. Di antara mereka $(37,0 \%)$ bahkan telah bekerja antara 11-14 tahun.

Di antara tiga sektor pada MNC Group, mayoritas $(68,0 \%)$ adalah responden yang berasal dari MNC Media. Kemudian 26,0\% responden yang bekerja di MNC Finance, dan yang paling sedikit $(6,0 \%)$ adalah responden yang bekerja di MNC Land. Komposisi responden seperti memang dilakukan secara purposive, sesuai dengan proporsi jumlah manager-up pada masing-masing dari ketiga sektor tersebut.

Suatu hal yang menarik adalah mayoritas responden $(92,0 \%)$ dalam enam bulan terakhir dapat mendengarkan secara langsung pidato Hary Tanoesoedibjo sebanyak 3-4 kali. Hal ini diduga mereka adalah manajer yang secara rutin mengikuti acara Manajer Forum yang memang diselenggarakan setiap tiga bulan sekali, yang berarti dua kali dalam enam bulan; plus ada kesempatan lain dapat mendengarkan secara langsung pidato Hary Tanoesoedibjo.

Jawaban hipotesis I, yaitu: besaran kontribusi pengaruh Core communication skills terhadap Effective leadership communications, dengan melihat nilai $\mathrm{R}^{2}$ ( $R$ Squared). Nilai 
Tabel 2 Core communication skills terhadap effective leadership communications

Model Summary

\begin{tabular}{cccccc}
\hline Model & $\mathrm{R}$ & $\begin{array}{c}\mathrm{R} \\
\text { Square }\end{array}$ & Adjusted R Square & Std. Error of the Estimate & Durbin-Watson \\
\hline 1 &, $124 \mathrm{a}$ &, 101 &, 093 & 1,461 & 1,485 \\
\hline
\end{tabular}

a. Predictors: (Constant), Core Communication Skills

b. Dependent Variable: Effective leadership Communication

Sumber: Hasil penelitian, 2018

$\mathrm{R}^{2}$ ( $R$ Squared) berada pada rentang 0 (nol) hingga 1 (satu), atau jika dipersentasekan antara $0 \%$ (nol persen) hingga 100\% (seratus persen). Jika $0 \%$ (nol persen) berarti tidak ada kontribusi pengaruh dari variabel independen (Core communication skills) terhadap variabel dependen (effective leadership communications), dan jika $100 \%$ berarti kontribusi pengaruh core communication skills terhadap effective leadership communications sudah maksimal, dan effective leadership communications tidak dipengaruhi variabel lain selain oleh variabel core communication skills.

Tabel 2 memperlihatkan bahwa angka $\mathrm{R}^{2}(\mathrm{R}$ Squared) adalah 0,101 yang berarti sumbangan/ kontribusi pengaruh Core communication skills terhadap effective leadership communications adalah $10,1 \%$. Hal ini berarti bahwa sisa pengaruh $(100 \%-10,1 \%=89,9 \%)$ dimiliki oleh variabel lain di luar core communication skills.

Jawaban Hipotesis II, yaitu: besaran kontribusi pengaruh managerial communication skills terhadap effective leadership communications, dengan melihat nilai $\mathrm{R}^{2}(R$ Squared). Nilai $\mathrm{R}^{2}$ ( $R$ Squared) berada pada rentang 0 (nol) hingga 1 (satu), atau jika dipersentasekan antara $0 \%$ (nol persen) hingga $100 \%$ (seratus persen). Jika 0\% (nol persen) berartitidakadakontribusi pengaruh darivariabel independen (managerial communication skills) terhadap variabel dependen (effective leadership communications), dan jika 100\% berarti kontribusi pengaruh managerial communication skills terhadap effective leadership communications sudah maksimal, dan effective leadership communications tidak dipengaruhi variabel lain selain oleh variabel managerial communication skills.

Pada Tabel 3 tampak bahwa angka $\mathrm{R}^{2}(R$ Squared) adalah 0,181 (18,1\%) yang berarti sumbangan/kontribusi pengaruh Managerial communication skills terhadap Effective leadership communications adalah 18,1\%. Hal ini berarti bahwa sisa pengaruh $(100 \%$ $18,1 \%=81,9 \%$ ) dimiliki oleh variabel lain di luar Managerial communication skills

Jawaban hipotesis III, yaitu: besaran kontribusi/sumbangan pengaruh Corporate communication skills terhadap Effective leadership communications, dengan melihat nilai $\mathrm{R}^{2}$ ( $R$ Squared). Pada Tabel 4 tampak bahwa angka $\mathrm{R}^{2}(R$ Squared $)$ adalah 0,177 $(17,7 \%)$ yang berarti kontribusi pengaruh Corporate communication skills terhadap Effective leadership communications adalah $17,7 \%$. Hal ini berarti bahwa sisa pengaruh $(100 \%-17,7 \%=82,3 \%)$ dimiliki oleh variabel lain di luar Corporate communication skills.

Tabel 3 Managerial communication skills effective leadership communications

\begin{tabular}{cccccc}
\multicolumn{6}{c}{ Model Summary $^{\mathrm{b}}$} \\
\hline Model & $\mathrm{R}$ & $\mathrm{R}$ & Adjusted R Square & Std. Error of the Estimate & Durbin-Watson \\
& & Square & & & 1,485 \\
\hline 1 &, $211 \mathrm{a}$ &, 181 &, 110 & 1,462 & 1,485 \\
\hline
\end{tabular}

a. Predictors: (Constant), Core Communication Skills

b. Dependent Variable: Effective leadership Communication

Sumber: Hasil penelitian, 2018 
Tabel 4 Corporate communication skills terhadap effective leadership communications

Model Summary ${ }^{\mathrm{b}}$

\begin{tabular}{cccccc}
\hline Model & $\mathrm{R}$ & $\mathrm{R}$ & Adjusted R Square & Std. Error of the Estimate & Durbin-Watson \\
& & Square & & & \\
\hline 1 & $191 \mathrm{a}$ &, 177 &, 140 & 1,457 & 1,473 \\
\hline
\end{tabular}

a. Predictors: (Constant), Corporate Communication Skills

b. Dependent Variable: Effective Internal Communication

Sumber: Hasil penelitian, 2018

Jawaban Hipotesis IV, yaitu: besaran kontribusi/sumbangan pengaruh core communication skills, managerial communication skills $\left(X_{2}\right)$, dan corporate communication skills $\left(X_{3}\right)$ secara simultan terhadap effective leadership communications $(\mathrm{Y})$, dengan melihat nilai $\mathrm{R}^{2}(R$ Squared). Nilai $\mathrm{R}^{2}$ ( $R$ Squared) berada pada rentang 0 (nol) hingga 1 (satu), atau jika dipersentasekan antara $0 \%$ (nol persen) hingga $100 \%$. Jika $0 \%$ (nol persen) berarti tidak ada pengaruh dari variabel independen (core communication skills) terhadap variabel dependen (effective leadership communications).

Analisis regresi linear berganda pengaruh variabel core communication skills, managerial communication skills, dan corporate communication skills secara simultan terhadap effective leadership communications. Pada Tabel 5. terlihat besaran pengaruh core communication skills, managerial communication skills $\left(X_{2}\right)$, dan orporate communication skills $\left(X_{3}\right)$ secara simultan terhadap effective leadership communications $(\mathrm{Y})$, dengan melihat nilai $\mathrm{R}^{2}(R$ Squared). Nilai $\mathrm{R}^{2}$ ( $R$ Squared) berada pada rentang 0 (nol) hingga 1 (satu), atau jika dipersentasekan antara 0\% (nol persen) hingga 100\%. Jika 0\% (nol persen) berarti tidak ada pengaruh dari variabel independen (core communication skills) terhadap variabel dependen (effective leadership communications).

Pada Tabel 6 tampak bahwa angka $\mathrm{R}^{2}$ (R Squared) adalah 0,228 (22,8\%) yang berarti sumbangan/ kontribusi pengaruh core communication skills, managerial communication skills, dan corporate communication skills secara simultan terhadap effective leadership communications adalah $22,8 \%$. Hal ini berarti sisanya 77,2\% dipengaruhi oleh variabel lain di luar variable penelitian.

Berdasarkan hasil pengolahan data seperti terlihat pada Tabel 7 Kolom unstandardized coefficients bagian B diperoleh persamaan regresi linier sederhana sebagai berikut:

$$
\begin{aligned}
& Y=\beta+b_{1} X_{1}+b_{2} X_{2}++b_{3} X_{3}+\varepsilon \\
& Y=37,262+0.037 X_{1}+0.024 \cdot X_{2}+0,081 X_{3}+
\end{aligned}
$$
$\varepsilon$

Keterangan:

$\mathrm{Y}=$ Effective leadership communication

$\mathrm{X}_{1}=$ Core communication skills

$\mathrm{X}_{2}=$ Managerial communication skills

$\mathrm{X}_{3}=$ Corporate communication skills

$\beta=$ Konstanta (nilai $Y^{\prime}$ apabila $X_{2}=0$ )

Tabel 5 Core communication skills, managerial communication ckills dan corporate communication Skills terhadap effective leadership communications

Model Summary ${ }^{\mathrm{b}}$

\begin{tabular}{cccccc}
\hline Model & $\mathrm{R}$ & $\begin{array}{c}\mathrm{R} \\
\text { Square }\end{array}$ & Adjusted R Square & Std. Error of the Estimate & Durbin-Watson \\
\hline 1 &, $241 \mathrm{a}$ &, 228 & 226 & 1,471 & 1,471 \\
\hline
\end{tabular}

a. Predictors: (Constant), Corporate Communication Skills

b. Dependent Variable: Effective Internal Communication

Sumber: Hasil penelitian, 2018 
Tabel 6 Core communication skills, managerial communication skills dan corporate communication skills terhadap effective leadership communications

Model Summary

\begin{tabular}{cccccc}
\hline Model & $\mathrm{R}$ & $\begin{array}{c}\mathrm{R} \\
\text { Square }\end{array}$ & Adjusted R Square & Std. Error of the Estimate & Durbin-Watson \\
\hline 1 & 24 &, 228 &, 226 & 1,471 & 1, \\
& $1^{\mathrm{a}}$ & & & & 4 \\
& & & & & 7 \\
\hline
\end{tabular}

a. Predictors: (Constant), Core Communication Skills

b. Dependent Variable: Effective leadership Communication

Sumber: Hasil penelitian, 2018

$\mathrm{b}_{1}=$ Koefisien regresi (nilai peningkatan ataupun penurunan)

$\varepsilon=$ outlier (pengaruh di luar variabel yang diteliti)

Dari persamaan regresi linear berganda seperti di atas terlihat sumbangan atau kontribusi masing-masing variabel independen terhadap effective leadership communication adalah sebagai berikut: a). Nilai konstanta ( $\beta)=37,262$. Ini mempunyai arti, bahwa, jika variabel Core communication skills, managerial communication skills, dan corporate communication skills dianggap konstan (tidak mengalami perubahan), maka effective leadership communications adalah sebesar 37,262. b). Koefisien $X_{1}\left(b_{1}\right)=0.03$. Berarti koefsien regresi variabel core communication skills terhadap effective internal communications sebesar 0.03 . Secara statistik ini mempunyai arti, bahwa setiap terjadi peningkatan variabel core communication skills sebesar 1 (satu) satuan, maka effective leadership communications akan meningkat sebesar 0.03. c). Koefisien $X_{2}$ $\left(b_{2}\right)=0.037$. Berarti koefsien regresi variabel managerial communication skills terhadap effective leadership communications sebesar 0.037 . Secara statistik ini mempunyai arti, bahwa setiap terjadi peningkatan variabel

Tabel 7 Konstanta dan koefisien pengaruh core communications, managerial Communication skills,

dan corporate communication skills terhadap effective leadership communications) Coefficientsa

\begin{tabular}{llllllllll}
\hline Model & & $\begin{array}{l}\text { Unstandardized } \\
\text { Coefficients }\end{array}$ & $\begin{array}{l}\text { Standardized } \\
\text { Coefficients }\end{array}$ & & & & & \multicolumn{2}{c}{$\begin{array}{c}\text { Collinearity } \\
\text { Statistics }\end{array}$} \\
\hline & B & Std. Error & Beta & T & Sig. & Tolerance & VIF \\
\hline 1 & 37,262 & 4,576 & & 8,144 &, 000 & & \\
& & (Constant) &, 091 &, 043 & 2,022 &, 029 &, 914 & 1,094 \\
& $\begin{array}{l}\text { Core Communication } \\
\text { Skills }\end{array}$ &, 037 &, 178 &, 014 & 2,133 &, 014 &, 936 & 1,069 \\
& $\begin{array}{l}\text { Managerial } \\
\text { Communication Skills } \\
\begin{array}{l}\text { Corporate } \\
\text { Communication Skills }\end{array}\end{array}$ &, 024 &, 081 &, 087 & 2,043 &, 041 &, 969 & 1,032 \\
\hline
\end{tabular}

a. Dependent Variable: Effective leadership Communication

Sumber: Hasil penelitian, 2018 
corporate communication skills sebesar 1 (satu) satuan, maka effective leadership communications akan meningkat sebesar 0.037 . d). Koefisien $X_{3}\left(b_{3}\right)=0.081$. Berarti koefsien regresi variabel corporate communication skills terhadap effective leadership communications sebesar 0.081. Secara statistik ini mempunyai arti, bahwa setiap terjadi peningkatan variabel corporate communication skills sebesar 1 (satu) satuan, maka effective leadership communications akan meningkat sebesar 0.081 .

Berdasarkan perumusan hipotesis, maka dapat dirumuskan pengujian hipotesis sebagai berikut:

$\mathrm{H}_{0}=\beta_{1}=\beta_{2}=\beta_{3}=0$ Core communication skills, Managerial communication skills, dan Corporate communication skills secara simultan tidak mempengaruhi Effective leadership communications.

$\mathrm{H}_{0} \neq \beta_{1} \neq \beta_{2} \neq 0$ Communication skills, Managerial communication skills, dan Corporate communication skills secara simultan mempengaruhi Effective leadership communications.

Adapun kriteria uji: Tolak hipotesis nol $\left(\mathrm{H}_{0}\right)$ dan terima hipotesis $\left(\mathrm{H}_{\mathrm{a}}\right)$, jika $\mathrm{F}$ hitung lebih besar daripada $\mathrm{F}$ table ( $\mathrm{F}$ hitung $>\mathrm{F}$ table) atau signifikan sama atau lebih kecil dari p-value (signifikan $\leq \mathrm{p}$-value). Berbeda dengan tiga model sebelumnya yang menyajikan pengaruh parsial.

Berdasarkan Tabel 8, secara statistik, hasil $\mathrm{F}$ hitung adalah $\mathbf{2 . 9 6 5}$, dan probabilitas (F-statistics) adalah $\mathbf{0 . 0 2 9}$ pada tingkat signifikansi $5 \%$. Sedangkan $\mathrm{F}$ tabel dengan jumlah $\mathrm{n}=100$ dan dengan df 3 (jumlah variable bebas- 1 ) $=4-1=3$ (pembilang), dan df 2 (n-k-1) atau 100-3-1=96 (penyebut), dimana $n$ adalah jumlah data, $\mathrm{k}$ adalah jumlah variabel independen) dengan menggunakan tingkat signifikansi 5\% (uji dua arah) diperoleh hasil Ftabel= 2.70. Dengan demikian F hitung (2.965) lebih besar daripada $\mathrm{F}$ table ( $\mathrm{F}$ hitung= $2.965>\mathrm{F}$ tabel $=2.70$ ). Selain itu signifikan sama atau lebih kecil dari p-value (signifikan $\leq p$-value), yakni 0.029. Berarti $\mathrm{H}_{0}$ ditolak, dan Ha diterima, yang artinya core communication skills $\left(X_{l}\right)$, managerial communication skills $\left(\mathrm{X}_{2}\right)$, dan corporate communication skills $\left(\mathrm{X}_{3}\right)$ secara simultan mempengaruhi effective internal communications (Y) secara positif dan signifikan. Dengan demikian hipotesis teruji bahwa core communication skills $\left(\mathrm{X}_{1}\right)$, managerial communication skills (X2), dan corporate communication skills (X3) secara simultan mempengaruhi effective internal communications (Y). Hasil perhitungan regresi menunjukan nilai signifikansi, artinya walaupun nilai kontribusi variabel $\mathrm{X}$ terhadap variabel $\mathrm{Y}$ rendah namun kontribusinya signifikan. Karena itu, hipotesisnya teruji.

Hasil penelitian di atas dapat kita diskusikan, pertama, memapankan kepemimpinan dalam suatu organisasi dapat dicapai dengan komunikasi internal menyangkut materi strategis. Dalam komunikasi internal tentang materi strategis, pemimpin harus menyampaikan visi, misi, dan strategi perusahaan kepada pegawainya, dan hal itu baru bisa dicapai jika pemimpin tersebut memiliki keterampilan yang memadai dalam berkomunikasi. Oleh karena itu efektif tidaknya komunikasi internal pemimpin dengan pegawainya tergantung pada sejauh mana keterampilan komunikasi pemimpin

Tabel 8 Uji Signifikasi ANOVA ${ }^{\mathrm{a}}$

\begin{tabular}{ccccccc}
\hline Model & & Sum of Squares & df & Mean Square & F & Sig. \\
\hline 1 & Regression & 1,721 & 3 &, 574 & 2,965 &, $029 \mathrm{~b}$ \\
& Residual & 207,669 & 96 & 2,163 & & \\
& Total & 209,390 & 99 & & & \\
\hline
\end{tabular}

a. Dependent Variable: Effective leadership Communication

b. Predictors: (Constant), Corporate Communication Skills, Managerial Communication Skills, Core Communication Skills 
tersebut (Barret, 2006).

Ketiga variabel independen tersebut mempngaruhi variabel dependennya, berarti ketiga variabel independen tersebut mempengaruhi indikator-indikator variabel dependen (Baret, 2006). Keterampilan komunikasi Chairman MNC selama ini berarti turut mempengaruhi manajemen yang mendukung efektivitas komunikasi tersebut (supportive management). Keterampilan komunikasi Chairman MNC berarti turut mempengaruhi pesan yang tertuju secara spesifik pada masing-masing sektor atau bahkan unit bisnis (targeted message). Keterampilan komunikasi Chairman MNC berarti turut mempengaruhi efektivitas media/ forum yang digunakan, tak terkecuali Manager Forum. Keterampilan komunikasi Chairman MNC berarti turut mempengaruhi ketepatan Chairman MNC dalam menempatkan staf yang bisa menjadi jembatan komunikasi antara Chairman MNC dengan segenap karyawannya. Keterampilan komunikasi Chairman MNC berarti turut mempengaruhi evaluasi dan penilaian mengenai efektivitas komunikasi secara berkala (ongoing assessment).

Kedua, Grup MNC merupakan konglomerasi yang cukup besar, sehingga jangkauan komunikasi chairman pada segenap karyawannya relatif terbatas. Manager Forum memang dianggap responden sebagai salah satu format komunikasi yang efektif, namun hanya terbatas pada peserta dengan jabatan manajer ke atas, dan dilaksanakan dengan frekuensi sangat jarang (tiga bulan sekali). Forum seperti itu lebih bersifat umum. Chairman cenderung menyampaikan pesan secara umum agar cocok dengan audience-nya yang memang berasal dari tiga sektor dan puluhan unit bisnis. Substansi komunikasi chairman yang sampai kepada segenap karyawan melalui Manager Forum, umumnya masih terbatas pada substansi visionary (misalnya tentang visi, misi maupun arah program tahunan korporasi). Substansi pesan dari chairman tersebut tentu kurang menyentuh hal-hal yang spesifik per sektor, lebih-lebih yang operasional; sehingga dirasakan kurang menyentuh persoalan operasional sehari-hari yang tengah dihadapi sebagian besar karyawan MNC Group pada masing-masing sektor, terutama pada masingmasing unit usaha. Inilah tantangan ke depan bagi MNC Group, yakni bagaimana agar pesan- pesan dari perusahaan tersebut juga bersifat lebih spesifik per sektor atau bahkan per unit bisnis.

Dalam hubungannya dengan teori struktural fungsional, unsur kepemimpinan Hary Tanoesoedibjo merupakan bagian dalam sebuah sistem yang berjalan di MNC Group. Oleh karena itu baik-buruknya atau majumundurnya MNC Group sedikit atau banyak bisa dipengaruhi oleh gaya kepemimpinan Hary Tanoesoedibjo, termasuk di dalamnya unsur keterampilan komunikasi Hary Tanoesoedibjo.

Penelitian ini juga memiliki implikasi manajerial. manajemen MNC Group penting untuk terus mengembangkan keterampilan komunikasi inti, komunikasi manajerial, dan komunikasi korporat. Pengembangan ketiga level keterampilan komunikasi pemimpin tersebut perlu dilakukan pada semua jajaran pimpinannya, yang bukan hanya jajaran direksi, namun juga jajaran manajer hingga supervisor. Hanya saja ada perbedaan dalam pemberlakuan. Keterampilan komunikasi level pertama (core communication skills) untuk jajaran supervisor; keterampilan komunikasi level pertama dan kedua (managerial communication skills) untuk jajaran manajerial. Sedangkan untuk jajaran direksi berlaku ketiga level, yakni level pertama, level kedua, dan level ketiga (corporate communication skills).

Keterampilan komunikasi inti yang perlu dikembangkan oleh manajemen MNC Group meliputi: (i) keterampilan mengelola kondisi/ situasi dan audience sebelum menyampaikan pidato atau public speaking dengan variasi bentuknya; (ii) keterampilan menyusun pesan yang khas/spesifik kepada audience yang berbeda; (iii) mampu memilih forum yang efektif; (iv) mampu membangun strategi komunikasi secara utuh (menagtyur intonasi; (v) meminta umpan baik dari audience, dan mampu menjawab pertanyaan audience; (vi) terampil berkomunikasi melalui tulisan (jelas, ringkas, mudah dipahami, percaya diri, tepat sasaran) termasuk penulisan formal sehingga menjadi efektif; (vii) mampu menyampaikan informasi dengan bahasa Indonesia secara jelas, baik, dan benar; (viii) menulis sendiri untuk pesan-pesan khusus dan kepada pihak-pihak yang khusus; (ix) mampu menyusun dan melakukan pidato atau presentasi secara mendadak (improvisasi), termasuk di luar bidang keilmuannya, termasuk pula menggunakan sejumlah perangkat lunak 
seperti power point (ppt); dan (x) mampu menjaga agar dirinya maupun audience tidak melenceng dari topik yang ditentukan.

Keterampilan komunikasi manajerial yang perlu dikembangkan oleh manajemen MNC Group meliputi: (i) keterampilan menetapkan tujuan dalam setiap meeting atau forum, (ii) keinginan untuk memperbaiki efektivitas komunikasi pribadi, (iii) mampu mempengaruhi perilaku orang lain, (iii) dapat menginspirasi kepercayaan orang lain, (iv) bersedia mendengarkan orang lain, (v) cukup peka terhadap perasaan. kondisi audience, misalnya yang sudah kelelahan; (vi) tidak berkeberatan jika harus berurusan dengan kemarahan orang lain; (vii) bisa bersikap hanya diam; (viii) bersedia me-mentoring orang lain mengenai komunikasi korporat; (ix) bersedia memperoleh bantun orang lain; (x) mengenali dengan baik latar belakang peserta audience; (xi) tidak segan memberikan pujian dan penghargaan kepada anak buahnya di tengah-tengah pidatonya; (xii) tidak menutup diri terhadap umpan balik yang disampaikan peserta.

Keterampilan komunikasi korporat yang perlu dikembangkan oleh manajemen MNC Groupmeliputi:(i)kemampuanmengembangkan komunikasi internal di perusahaan; (ii) kemampuan mengembangkan visi perusahaan dengan baik; (iii) mengkomunikasikan visi perusahaan kepada pemangku kepentingan yang relevan; (iv) mampu menargetkan pesan ke tingkat yang berbeda dalam perusahaannya; (v) dapat menciptakan wahana/forum dalam cara komunikasinya; (vi) dapat mengembangkan strategi komunikasi eksternal perusahaan; (vii) sungguh-sungguh dalam me-manage citra korporat; (viii) dapat menganalisis kebutuhan pemangku kepentingan eksternal perusahaan; dan (ix) sering berkomunikasi dengan jurnalisjurnalis media baru.

Hasil penelitian ini mendukung sejumlah penelitian terdahulu, yaitu: Penelitian (Zervas, Vercic, \& Wiesenberg, 2016: 43) yang menekankan pentingnya keterampilan komunikasi yang harus dimiliki oleh pemimpin suatu organisasi. Penelitian (Johansson, Miller, \& Hamrin, 2014: 156) yang menyatakan tema komunikasi yang efektif yang penting dilakukan oleh seorang pemimpin. Jika penelitian ini mengklasifikasikan keterampilan komunikasi pemimpin menjadi tiga level (core, managerial, dan corporate), maka penelitian tersebut menyebut empat perilaku komunikatif, yakni structuring, facilitating, relating, dan representing. Penelitian (Hamrin, 2016) menjelaskan tentang efektivitas komunikasi yang efektif.

\section{SIMPULAN}

Berdasarkan hasil penelitian dengan memerhatikan rumusan, tujuan, dan hipotesis penelitian, maka dapat disimpulkan bahwa variabel Core communication skills, managerial communication skills, dan corporate communication skills secara parsial memengaruhi effective leadership communications secara positif dan signifikan. Hal ini berarti hipotesis penelitian ini terbukti.

Ketiga variabel (core communication skills, managerial communication skills, dan corporate communication skills) secara parsial maupun simultan memengaruhi effective internal communication, karena indikator-indikator dalam ketiga variabel independen dapat mendukung terjadinya komunikasi internal perusahaan secara efektif. Tanpa memenuhi indikator-indikator dalam communication skills, maka seorang pemimpin akan cenderung gagal dalam melakukan komunikasi secara internal dalam perusahaan, baik dengan jajaran direksi/komisaris maupun para pegawai secara keseluruhan.

Dari hasil tersebut terlihat bahwa banyak variabel independen lain yang turut memengaruhi dan bisa menjelaskan variabel dependen yaitu effective leadership communications. Oleh karena itu untuk penelitian selanjutnya disarankan agar menambahkan variabel independen lain yang masih berada pada koridor ilmu komunikasi. Hal ini terkait implikasi teoritis.

Rekomendasi dari penelitian ini mengingat korporasi MNC semakin hari semakin besar, maka dapat dipertimbangkan membentuk forum-forum yang lebih kecil dan spesifik.

\section{DAFTAR PUSTAKA}

Argenti, P. A. (2010). Komunikasi korporat (corporate communications) (Vol. Edisi 5). Jakarta, DKI Jakarta, Indonesia: Salemba Humanika.

Barret, D. (2013). Leadership communication. Bandung, Jawa Barat, Indonesia: McGraw- 
Hill Education.

Christensen, L. T. \& Cornelissen, J. (2010). Bridging corporate and organizational communication: review development and a look to the future. Management Communication Quarterly, 25 (3), 383414.

Eccles, R. G. \& Nohria, N. (1991). The post structuralist organization. NewYork, America: Division of Research, Harvard Business School.

Gaines-Ross, L. (2008). Corporate reputation: 12 steps to safeguarding and recovering reputation. Inggris: Wiley.com.

Hallahan, K., Holtzhausen, D., Ruler, B. v., Vercic, D., \& Sriramesh, K. (2007). Defining strategic communication. International Journal of Strategic Communication, 1 (1), 3-35.

Hamrin, S. (2016). Communicative leadership and contextin discourses of leadership practices. Corporate Communication: An International Journal, 21 (3), 371-387.

Johansson, C., Miller, V. D., \& Hamrin, S. (2014). Conceptualizing communicative leadership: a framework for analysing and developing leaders' communication competence. Journal of Corporate Comunications, 19 (2), 147-165.

Lahoreschool, f. (2017). Structural functional. faculty.lahoreschool.edu.pk/academics/ lectures/anis/functionalism. India, India.

Livingstone, S. (2009). On Mediation of everything: ica presidential address 2008 . Journal of Communication, 59 (1), 1-18.

Lundby, K. (2009). Mediatization: concept, change, consequences. (K. Lundby, Ed.) New York, America: Peter Lang.

Meng, J. \& Berger, B. (2013). An integrates model of excellent leadership in public relations: dimensions, measurement and validation. Journal of Public Relations Research, 25 (2), 141-167.

Mukhtar, Ali, H. \& Jannah, S. R. (2016). Leadership style and organizational culture effect on career development at ministry religious affairs in Jambi Province. IOSRJournal of Business and Management (IOSR-JBM, 18 (11), 65-74.

Nessmann, K. (June 2009). Personal communication management; how to position people effectively. In T. Ralf, D. Sandra, \& K. Mathias (Ed.), Proceedings of the 8th ICORIA (International Conference on Research Advertising) (pp. 1-7). Austria: University of Klagenfurt.

Pollach, I. \& Kerbler, E. (2011). Appearing competent (a study of impression management in us and european ceo profiles. International Journal of Business Communication, 48 (4), 355-372.

Ruler, B. V. \& Vercic, D. (2005). Reflective communication management, future ways for public relations research. Annals of The International Communication Association, 29 (Communication Yearbook 29), 239274.

Smith, R. D. (2013). Strategic Planning for Public Relations (Vol. 4th Edition). New York, America: Routledge.

Tabachnick, B. \& Fidell, L. S. (2013). Using Multivariate Statistics (Sixth Edition ed., Vol. 6). Boston, Amerika, USA: Pearson Education, Inc.

Zervas, A., Vercic, D., \& Wiesenberg, M. (2016). Managing CEO Communication and Positioning: A Cross National Study Among Corporate Communication Leaders. Journal of Communication Management, 20 (1), 37-55.

Tabachnick, B. \& Fidell, L. S. (2013). Using Multivariate Statistics (Sixth Edition ed., Vol. 6). Boston, Amerika, USA: Pearson Education, Inc.

Zervas, A., Vercic, D., \& Wiesenberg, M. (2016). Managing ceo communication and positioning: a cross national study among corporate communication leaders. Journal of Communication Management, 20 (1), $37-55$. 